\title{
Local Overexpression of TIMP-1 Prevents Aortic Aneurysm Degeneration and Rupture in a Rat Model
}

\author{
Eric Allaire, ${ }^{\star}$ Reza Forough, ${ }^{\ddagger}$ Monika Clowes, ${ }^{\S}$ Barry Starcher, ${ }^{\|}$and Alexander W. Clowes ${ }^{\S}$ \\ *Service de Chirurgie Vasculaire, Hôpital H. Mondor, 94010 Créteil, France; ${ }^{\ddagger}$ Department of Medical Physiology, Texas A and M \\ University Health Science Center, College Station, Texas 77843; ${ }^{\S}$ Department of Surgery, University of Washington, Seattle, Washington \\ 98195-6410; and ${ }^{\|}$Department of Biochemistry, University of Texas Health Center at Tyler, Tyler, Texas 75710
}

\begin{abstract}
Although matrix metalloproteinases (MMPs) are expressed in abundance in arterial aneurysms, their contribution to arterial wall degeneration, dilation, and rupture has not been determined. We investigated MMP function in a rat model of aneurysm associated with arterial dilation, elastin loss, medial invasion by mononuclear inflammatory cells, and MMP upregulation. Rupture was correlated with increased gelatinase B (MMP-9) and activated gelatinase A (MMP-2). Syngeneic rat smooth muscle cells retrovirally transfected with tissue inhibitor of matrix metalloproteinases (TIMP)-1 cDNA (LTSN) or with the vector alone as a control (LXSN) were seeded onto the luminal surface of the vessels. The seeding of LTSN cells resulted in TIMP-1 local overexpression. The seeding with LTSN cells, but not LXSN cells, decreased MMP-9, activated MMP-2 and 28-kD caseinase and elastase activity, preserved elastin in the media, and prevented aneurysmal degeneration and rupture. We conclude that MMP overexpression is responsible for aneurysmal degeneration and rupture in this rat model and that local pharmacological blockade might be a reasonable strategy for controlling the formation of aneurysms in humans. $(J$. Clin. Invest. 1998. 102:1413-1420.) Key words: matrix metalloproteinases • pharmacology • TIMP-1 • xenograft • aneurysm
\end{abstract}

\section{Introduction}

Aneurysmal degeneration of the aorta is associated with loss of elastin (1-4) and medial and adventitial inflammation (5-7). The significance of extracellular matrix loss in arterial dilation and rupture is suggested by in vitro and in vivo studies (8-10), but the mechanisms have not been defined. High levels of collagen and elastin synthesis have been observed in human aneurysms (11); thus, the deficit might be due in part to excessive matrix degradation by proteases. Matrix metalloproteinases $(\mathrm{MMPs})^{1}$ have been extensively studied in aneurysms because they can degrade most of the arterial extracellular matrix com-

Address correspondence to Alexander W. Clowes, M.D., Department of Surgery, University of Washington School of Medicine, 1959 NE Pacific Street, HSB Box 356410, Seattle, WA 98195-6410. Phone: 206-543-9890; FAX: 206-616-7495; E-mail: clowes@u.washington.edu

Received for publication 26 January 1998 and accepted in revised form 22 July 1998.

J. Clin. Invest.

(C) The American Society for Clinical Investigation, Inc. 0021-9738/98/10/1413/08 \$2.00

Volume 102, Number 7, October 1998, 1413-1420

http://www.jci.org ponents, including elastin and collagen (12-16). Their expression could be regulated by the interplay of inflammatory cells and cytokines present in the aneurysmal wall (17-19). Some reports have found higher MMP content in aortic aneurysms compared with aortas with occlusive disease (20), while others have not (21). The differences in long-term outcome might be explained by the observation that the increase in MMPs can be localized to the media and adventitia of aortic aneurysms, whereas most of the proteolytic enzymes in atherosclerotic aortas is confined to the intima $(21,22)$.

We have made the observation that segments of guinea pig aorta depleted of cells orthotopically grafted into rats become aneurysmal within weeks (23). This chronic rejection process is related to the immunogenicity of the xenograft (10). Elastin in the media is destroyed in association with the invasion of monocyte-macrophages and $\mathrm{T}$ lymphocytes and the accumulation of immunoglobulins $(10,24)$. The dilating arterial xenografts share many aspects of human aneurysmal disease including loss of elastin and the infiltration of inflammatory cells (25).

In the present study, we have used this model to define the role of MMPs in aneurysm formation and rupture by modulating the proteolytic burden in the graft. The increase in MMP activity resulted in accelerated elastin resorption and graft rupture, whereas the blockade of MMP activity by local overexpression of tissue inhibitor of matrix metalloproteinases (TIMP)-1, an inhibitor of MMPs, prevented elastin depletion, aneurysm formation, and rupture. These experiments provide evidence that an altered balance of proteases and inhibitors affects vascular structure.

\section{Methods}

Animal model. Male Fischer 344 rats (250 g) and male Hartley guinea pigs (400 g; Simonsen Laboratories Inc., Gilroy, CA) were housed and cared for in the animal facility of the University of Washington School of Medicine, Seattle. All animal experimentation complied with the National Institutes of Heath guidelines (NIH publication 86-23). All protocols were approved by the Animal Care Committee of the University of Washington School of Medicine.

Orthotopic engraftment of 10-mm-long segments of decellularized guinea pig aorta (xenograft) into Fischer 344 rat abdominal aorta was performed as previously described (23). Decellularization was done by incubating the grafts in $0.1 \%$ SDS to obtain arterial extracellular matrix without cells (10). To obtain xenograft rupture, we took advantage of the fact that the xenogeneic arterial extracellular matrix is immunogenic (10). Fischer 344 rats (5 wk old, $80 \mathrm{~g}$ ) were immunized by repeated injections of homogenized decellularized guinea

1. Abbreviations used in this paper: MMP, matrix metalloproteinase; MMP-2, 72 kD gelatinase A; MMP-3, stromelysin-1; MMP-9, $92 \mathrm{kD}$ gelatinase B; MMP-12, macrophage elastase; TIMP, tissue inhibitor of matrix metalloproteinases. 
pig arterial extracellular matrix in $0.9 \% \mathrm{NaCl}$ with no adjuvant before transplantation (preimmunization).

Seeding of TIMP-1-transduced cells. Syngeneic Fischer 344 rat smooth muscle cells were transduced in vitro with baboon TIMP-1 cDNA (LTSN cells). The preparation of the replication-defective retrovirus-encoding baboon TIMP-1 (LTSN) and the isolation and transduction of the Fischer 344 rat smooth muscle cells have been described in previous publications $(26,27)$. The control retroviral vector (LXSN) lacks the baboon TIMP-1 cDNA (28). The LTSN cells express a 4.0 -kb TIMP-1 transcript that is larger than normal $(0.9 \mathrm{~kb})$ because of the additional retroviral coding sequence including neomycin phosphotransferase. They secrete active TIMP-1 ( $\left.\mathrm{M}_{\mathrm{r}} 28 \mathrm{kD}\right)$ continuously in the media.

Immediately after graft implantation, LXSN or LTSN Fischer 344 rat smooth muscle cells suspended in 5\% BSA were seeded into the lumen of the grafts $\left(10^{8}\right.$ cells/graft $)$ through a PE 10 catheter introduced through a transverse aortotomy and were allowed to attach for $10 \mathrm{~min}$. The aortotomy was closed with a 10/0 Ethicon suture, and flow was reestablished. Graft diameter was measured immediately after transplantation (D0) and before euthanasia at $4 \mathrm{wk}$ (D4w). The diameter increase for each graft was calculated as follows: (D4w - D0) $\times$ 100/D0. The graft was considered to be aneurysmal if the diameter had increased by more than $100 \%$.

Histology and immunohistochemistry. Cryostat cross sections (5 $\mu \mathrm{m})$ were made from the center of grafts harvested at $3 \mathrm{~d}$ and fixed with cold methanol (24). Primary monoclonal mouse anti-rat antibodies were ED1 for monocytes and macrophages and R73 for T cells (Harlan Bioproducts for Science Inc., Indianapolis, IN). The secondary antibody was a biotinylated anti-mouse IgG raised in horse (Vector Laboratories Inc., Burlingame, CA). The tissue sections were then incubated in avidin-biotin-peroxidase complex with Vector ${ }^{\circledR}$ Red as substrate according to the manufacturer's recommendations (Vectastain ${ }^{\circledR}$ Elite ABC Kit; Vector Laboratories Inc.). Control sections were treated in the same way except an irrelevant primary mouse antibody was used.

Elastin assay. Desmosine, an amino acid present only in elastin, was quantified as a measure of elastin content in the tissue. The samples (5-mm segments) were freeze-dried, weighed, and hydrolyzed in $6 \mathrm{~N} \mathrm{HCl}$ at $105^{\circ} \mathrm{C}$ for $24 \mathrm{~h}$. The samples were evaporated to dryness and redissolved in $500 \mu \mathrm{l}$ of distilled water, and the radioimmunoassay for desmosine was performed in triplicate on 5- $\mu$ l samples, as described previously (29).

Detection of TIMP activity in graft extracts by reverse zymography. Pools of three grafts were extracted with $0.05 \mathrm{M}$ Tris $\mathrm{pH} 7.5$ buffer containing $0.01 \mathrm{M} \mathrm{CaCl}_{2}, 2 \mathrm{M}$ guanidine, and $0.2 \%$ Triton $\mathrm{X}-100$ and dialyzed against $0.05 \mathrm{M}$ Tris, $0.2 \%$ Triton X-100, pH 7.5 for $48 \mathrm{~h}$ at $4{ }^{\circ} \mathrm{C}$. For reverse zymography, protein extracts were subjected to $10 \%$ SDS PAGE containing $1 \%$ gelatin and active $72 \mathrm{kD}$ gelatinase (Reverse Zymography Kit; University Technologies Intl. Inc., Calgary, Canada). This kit contains TIMP standards. After incubation at $37^{\circ} \mathrm{C}$, the gels were stained with Coomassie Blue. TIMP activity appeared as a dark band where MMP-related gelatinase activity was blocked.

Detection of TIMP-1 protein by Western blotting. Protein extracts $(20 \mu \mathrm{g})$ were subjected to $10 \%$ SDS PAGE, transferred onto a nylon membrane, and blocked with $3 \%$ BSA. The primary antibody was a polyclonal anti-human TIMP-1 (gift from Dr. H. Welgus, Washington University, St. Louis, MO). The secondary antibody was an antirabbit IgG conjugated to alkaline phosphatase (Promega Corp., Madison, WI; dilution 1:7500), and the substrate for alkaline phosphatase was nitro blue tetrazolium and 5-bromo-4-chloro-3-indolyl phosphate (Promega). Controls included incubation with a nonimmune serum (American Diagnostica Inc., Greenwich, CT).

Detection of matrix metalloproteinase activity. Pools of three grafts were extracted as described for TIMP-1 activity detection. Equal amounts of extracted proteins were subjected to $10 \%$ SDS PAGE in gels containing $1 \%$ gelatin, $1 \%$ casein (Sigma Chemical Co., St. Louis, MO), or ETNA elastin (Elastin Product Co. Inc., Owensville,
$\mathrm{MO}$ ), rinsed in $2.5 \%$ Triton $\mathrm{X}-100$, incubated for $18 \mathrm{~h}$ at $37^{\circ} \mathrm{C}$, and stained with $0.008 \%$ Coomassie Blue R (Sigma Chemical Co.). For quantification, gelatin zymograms were scanned with a Hewlett Packard ScanJet 3C/T using Adobe Photoshop 3.0. MMP-9- and MMP-2related bands $(110,92.5,85$, and $80 \mathrm{kD}$ and 72 and $64 \mathrm{kD}$, respectively) were quantified with Image Quant v3.3 (Molecular Dynamics, Sunnyvale, CA). Results were plotted against a standard curve generated on the same gel with purified human MMP-9 and MMP-2 (gift from Dr. H. Welgus).

To determine whether the proteolytic activities on the zymograms were due to MMPs, inhibitors of MMPs (30 mMol EDTA [Sigma Chemical Co.] or rTIMP-1 [a gift from Dr. H. Nagase, University of Kansas, Kansas City, KS]) or serine proteases (1 mM PMSF [Sigma Chemical Co.]) were added to the incubating buffer. Activation of MMPs was obtained after 1-h incubation of extracts in $1 \mathrm{mM}$ 4-aminophenyl mercuric acetate at $37^{\circ} \mathrm{C}$ (Sigma Chemical Co.) (30).

TIMP inactivates MMPs by forming complexes (12). TIMP inhibitory activity can be irreversibly abolished by reduction followed by alkylation (31). To demonstrate whether changes in proteolytic activity were related to decreased MMP expression or blockade by TIMP, graft extracts were incubated with $2.5 \mathrm{mM}$ dithiothreitol followed by $5 \mathrm{mM}$ iodoacetamide at $37^{\circ} \mathrm{C}$. Similar amounts of grafts extracts were incubated in parallel with distilled water as a control. The products were then analyzed by quantitative zymography as described above.

Zymography for plasminogen activators. Since plasminogen activators may play a role in aneurysm formation $(32,33)$, we have investigated the impact of TIMP-1 overexpression on tPA and uPA activity in the seeded vessels. Pools of three grafts in each group were cut with razor blades, crushed in a mortar, and extracted in iced buffer containing $75 \mathrm{mM}$ potassium acetate, $0.3 \mathrm{M} \mathrm{NaCl}, 0.1 \mathrm{M}$ L-arginine, and $10 \mathrm{mM}$ EDTA in $0.25 \%$ Triton $\mathrm{X}-100, \mathrm{pH} 4.2$, for $15 \mathrm{~min}$ (34) and centrifuged at 10,000 rotations per minute for $10 \mathrm{~min}$ at $4^{\circ} \mathrm{C}$. Protein content in the supernatant was measured against a BSA standard. Equal protein amount in each group was subjected to $10 \%$ SDS PAGE. The gel was rinsed in $2.5 \%$ Triton X-100 and incubated in $1 \times$ PBS for $20 \mathrm{~min}$ each. The gel was applied to an agar gel containing milk casein and human glu-type plasminogen (American Diagnostica Inc.) in $1 \%$ agarose (35). After incubation at $37^{\circ} \mathrm{C}$ in a moist chamber, gels were photographed using dark-field illumination. Areas of casein lysis appeared as dark areas in a white background. tPA and uPA were identified by incorporating selective inhibitors into the gel (anti-human tPA \#387 from American Diagnostica Inc. and $1 \mathrm{mM}$ amiloride from Sigma Chemical Co., respectively) (35).

Statistical analysis. All results are expressed as mean \pm SD. Comparisons between two groups of grafts were done using a Mann-Whitney U test. Comparisons between three groups used a Kruskall-Wallis one-way ANOVA. If the one-way ANOVA showed significant differences, pairwise comparisons were done with a Dunn's test. $P<$ 0.05 was accepted as significant.

\section{Results}

\section{Effects of preimmunization}

Grafts placed in naive animals became aneurysmal by 4 wk after implantation, although none of them ruptured. All rats immunized with guinea pig aortic extracts before xenograft transplantation expired between day 4 and 14 from graft rupture and retroperitoneal haemorrhage. Inflammatory cell penetration into the media and medial elastin degradation at day 3 after transplantation was accelerated in these grafts compared with grafts implanted in naive rats (Fig. $1, A-C$ ).

MMP-9 and MMP-2 in xenograft extracts were identified based on the molecular weight of their bands of gelatinolytic activity (110-80 kD for MMP-9, and 72 and $64 \mathrm{kD}$ for MMP-2) $(36,37)$. The proteolytic activity was inhibited by EDTA and 


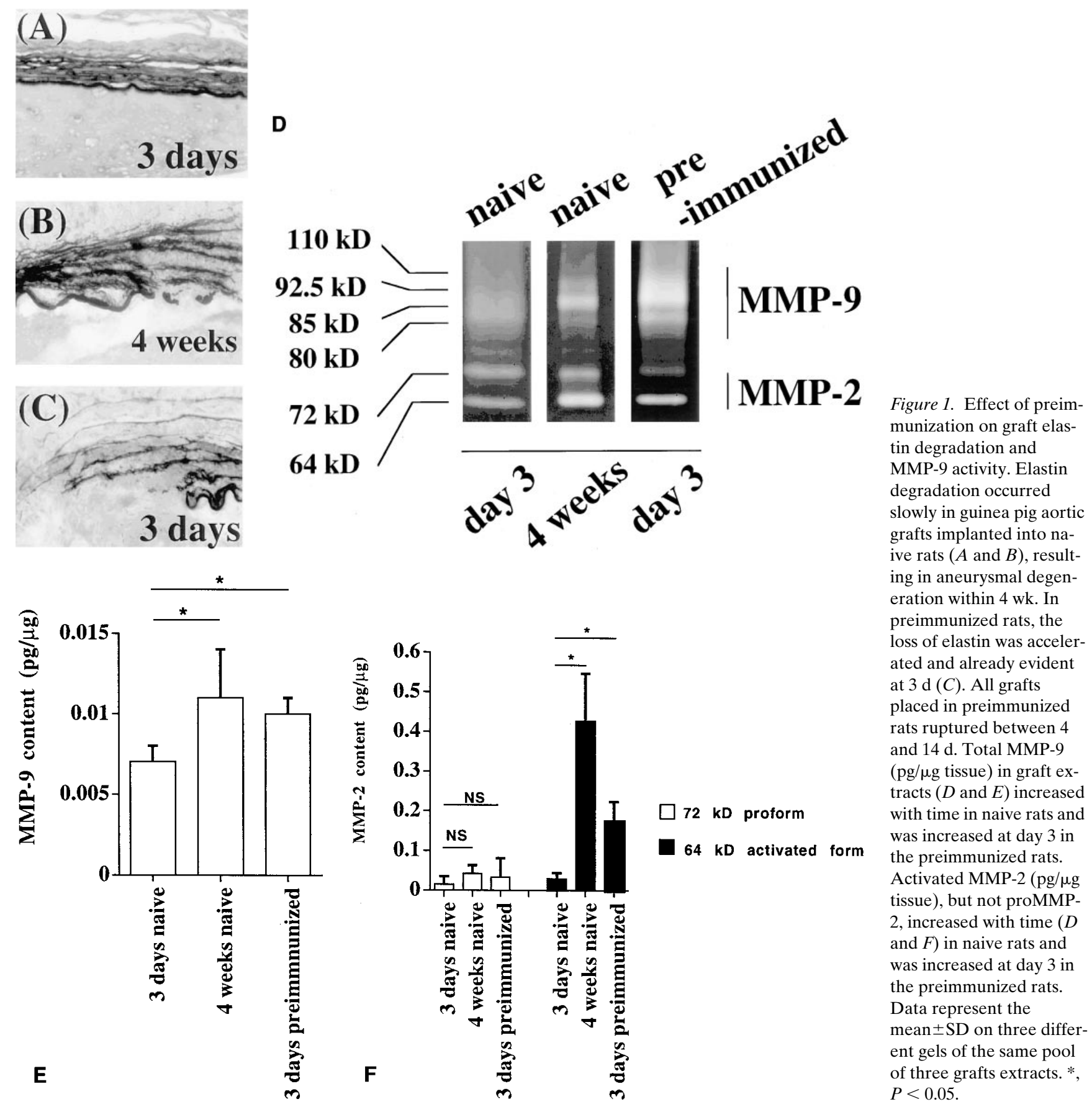

rTIMP-1 but not by PMSF (data not shown). No MMPs were detected in xenografts before implantation; MMP-2, but not MMP-9, was detected in normal ungrafted rat aortas (data not shown). MMP-9 activity at day 3 was increased in grafts implanted in preimmunized rats in comparison with grafts implanted in nonpreimmunized rats (Fig. 1, D and E). Preimmunization produced an increase in 64-kD gelatinase activity, the activated form of MMP-2, but not the $72-\mathrm{kD}$ proform of the enzyme (36) (Fig. 1, $D$ and $F$ ).

\section{Expression of TIMP-1 protein and activity}

TIMP-1 protein and activity were detected in the LTSN cellseeded vessels but not the LXSN cell-seeded controls (Fig. 2, $A$ and $B$ ). TIMP-1 was present not only in the graft intima where LTSN cells had been seeded but also in the graft media and adventitia. Low levels of TIMP-2 activity were detected on reverse zymograms in all seeded grafts (Fig. $2 B$ ).

\section{Graft diameter, length, and rupture in preimmunized rats}

In preimmunized rats, the cumulative rupture rate over a period of $4 \mathrm{wk}$ in LXSN cell-seeded grafts was $50 \%$ as compared with $100 \%$ for nonseeded grafts. All the other nonruptured LXSN cell-seeded grafts were aneurysmal at 4 wk (Fig. $3 A$ ). The LTSN cell-seeded grafts in preimmunized rats over the same period of time did not rupture, were not aneurysmal, and did not elongate (Fig. 3, $A-C$ ). In naive rats, the seeding with either LXSN or LTSN cells prevented aneurysm formation and graft elongation at $4 \mathrm{wk}$ after engraftment (Fig. 3, $B$ and $C$ ). 


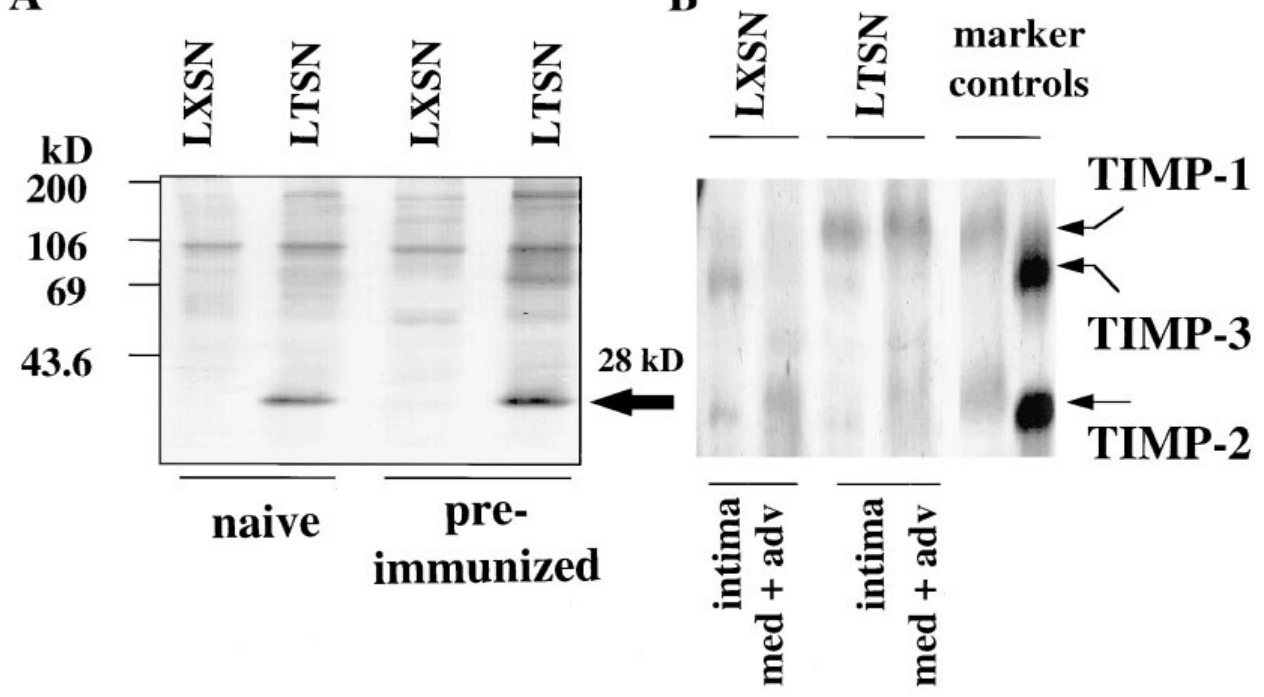

Figure 2. Local overexpression of TIMP-1 protein and activity at $4 \mathrm{wk}$. (A) TIMP-1 protein was detected by Western blotting of extracts of grafts seeded with control $(L X S N)$ or TIMP-1 (LTSN) cells retrieved from naive or preimmunized rats. (B) The intimas of three grafts from preimmunized rats were separated from the media and adventitia, and TIMP-1 activity was detected by reverse zymography. med, media; adv, adventitia.

\section{Elastin network and desmosine content}

Since medial elastin degradation is a determinant of aneurysmal degeneration, we investigated the effect of LXSN and LTSN cell seeding on elastin content in the grafts. Cross-sectional examination of xenografts showed a complete loss of elastin in the aneurysmal grafts (LXSN cell-seeded grafts implanted in the preimmunized rats), while in the nonaneurysmal grafts (LXSN and LTSN cell-seeded grafts in naive rats and LTSN cell-seeded grafts in preimmunized rats), the elastin layers were largely intact (Fig. 3, D-G). The loss of desmosine also correlated with aneurysmal degeneration (Fig. $3 H$ ). For example, in the grafts of naive rats, seeding of LXSN or LTSN cells preserved desmosine and prevented aneurysmal dilation. On the other hand, in the grafts of preimmunized rats, only the LTSN cells were able to prevent dilation and desmosine loss.

MMP activity in the seeded grafts at day 3 in preimmunized rats

Gelatin zymography. Total MMP-9 gelatinolytic activity was decreased in the LTSN cell-seeded grafts compared with LXSN cell-seeded grafts (Fig. 4, $A$ and $B$ ). After elimination of TIMP activity in graft extracts by reduction-alkylation, MMP-9 activity was similar in LTSN cell- and LXSN cellseeded grafts (Fig. $4 \mathrm{~B}$ ). Therefore, the decrease of MMP-9 activity was due to formation of complexes with TIMP and not to a lowering of total MMP-9 present in the graft. Activated (64 kD) MMP-2 was decreased in extracts of the LTSN cellseeded grafts as compared with the LXSN cell-seeded vessels (Fig. $4 A$ ). This activity did not change with reduction-alkylation.

Casein and elastin zymography. A $28-\mathrm{kD}$ band was detected by casein zymography in LXSN cell-seeded grafts and was markedly decreased in LTSN cell-seeded grafts (Fig. $4 C$ ). The band was not altered by reduction-alkylation but could be eliminated by treatment with EDTA or rTIMP-1 (data not shown). A 28-kD MMP (inhibited by EDTA and rTIMP-1) was also detected by elastin zymography (Fig. $4 \mathrm{D}$ ) in the LXSN cell-seeded grafts but not in the LTSN cell-seeded grafts; a 54-kD band was found in the LTSN cell-seeded graft extracts. Reduction-alkylation did not change these elastinolytic bands (data not shown).
Effect of TIMP-1 overexpression on plasminogen activator activity

As published elsewhere (32), the main plasminogen activator in graft extracts was tPA. tPA activity on casein zymography was similar in LXSN and LTSN cell-seeded vessels (data not shown). uPA was barely detectable in these extracts.

\section{Graft infiltration by inflammatory cells}

Monocyte-macrophages (ED1 ${ }^{+}$cells) were the predominant leukocyte in the wall; $<5 \%$ of the cells were $\mathrm{T}$ lymphocytes $\left(\mathrm{R}_{3}{ }^{+}\right.$cells). The density of $\mathrm{ED} 1^{+}$cells recruited in the graft intima, media, and adventitia was similar in the two groups of seeded grafts at day $3\left(5.0 \pm 1.0\right.$ and $4.3 \pm 1.1 \times 10^{3}$ cells $/ \mathrm{mm}^{2}$ in LXSN and LTSN cell-seeded grafts, respectively, Mann-Whitney $U$ test: $P=0.51$, nonsignificant). At late times, quantification of medial inflammatory cells in LXSN cell-seeded grafts was not possible since the elastin layers were almost completely destroyed.

\section{Discussion}

We have used a cell-based gene transfer approach to define the role of MMPs in a rat xenograft model of human aortic aneurysm. We demonstrate that MMP activity is increased in this model. If MMP activity is blocked by local overexpression of TIMP-1, aneurysmal dilation and rupture are prevented.

The model of human aortic aneurysms. In rat arterial xenografts and human aneurysms, the media and adventitia are depleted of mesenchymal cells and are infiltrated with mononuclear phagocytes and $\mathrm{T}$ lymphocytes, immunoglobulins are deposited, and elastin layers are destroyed $(10,38)$. These aneurysmal vessels eventually rupture. The cause of abdominal aortic aneurysm development in humans is unknown. Autoimmunity might be part of the process $(39,40)$; whether it is a trigger or a consequence of arterial extracellular matrix damage is unknown. Nevertheless, the monocyte-macrophages and $\mathrm{T}$ lymphocytes present in both the xenograft model and human aneurysms are a source of extracellular matrix degrading enzymes, just as they are in other inflammatory tissues such as atherosclerotic plaques and arthritic joints $(25,41)$. Macrophages and $\mathrm{T}$ lymphocytes communicate through the 


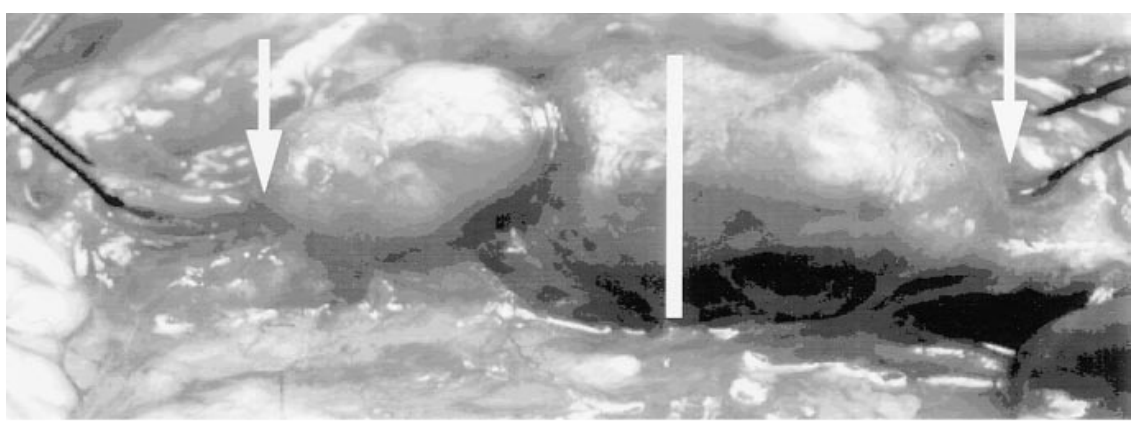

A
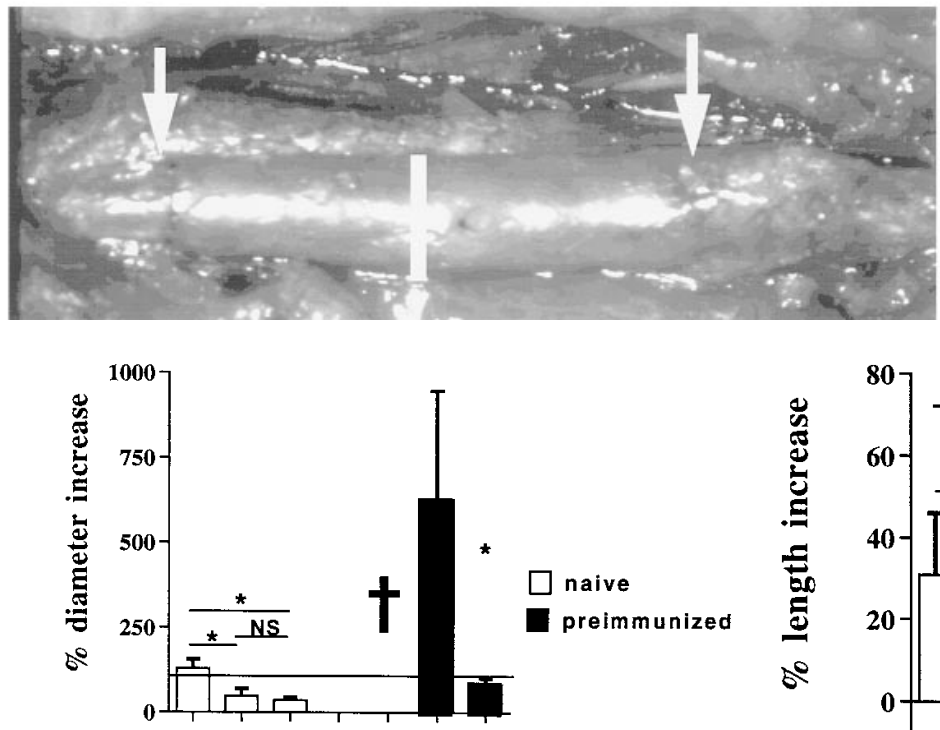

number of grafts: number of ruptures:
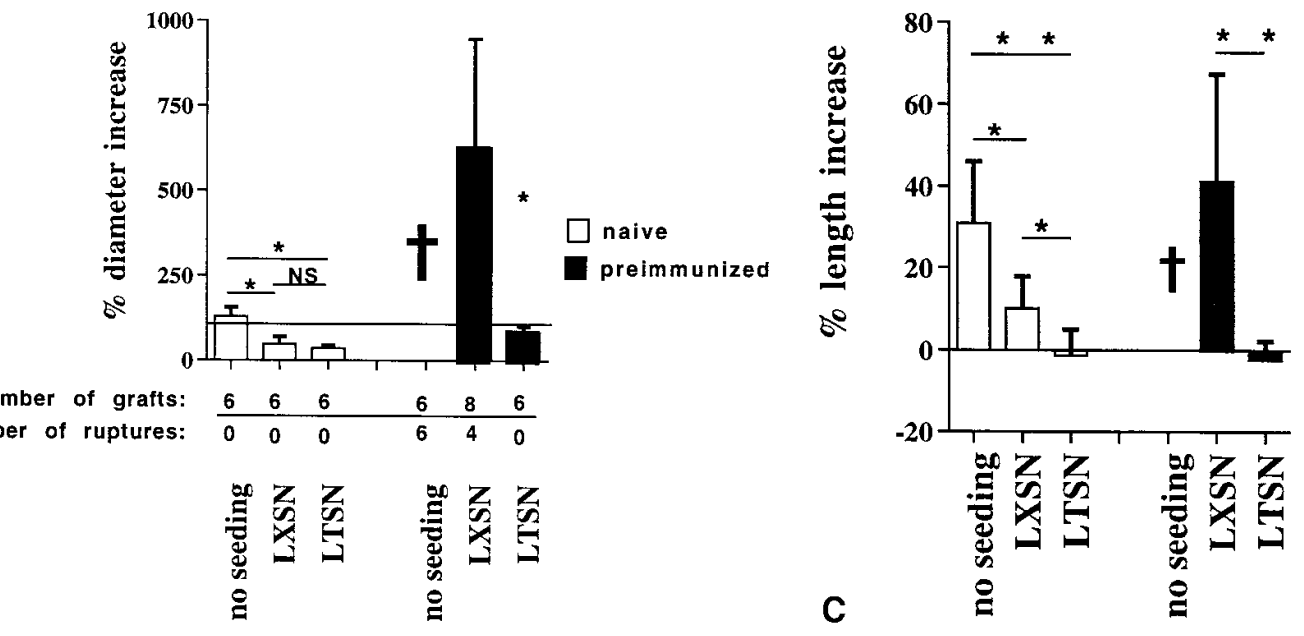

naive

preimmunized

B
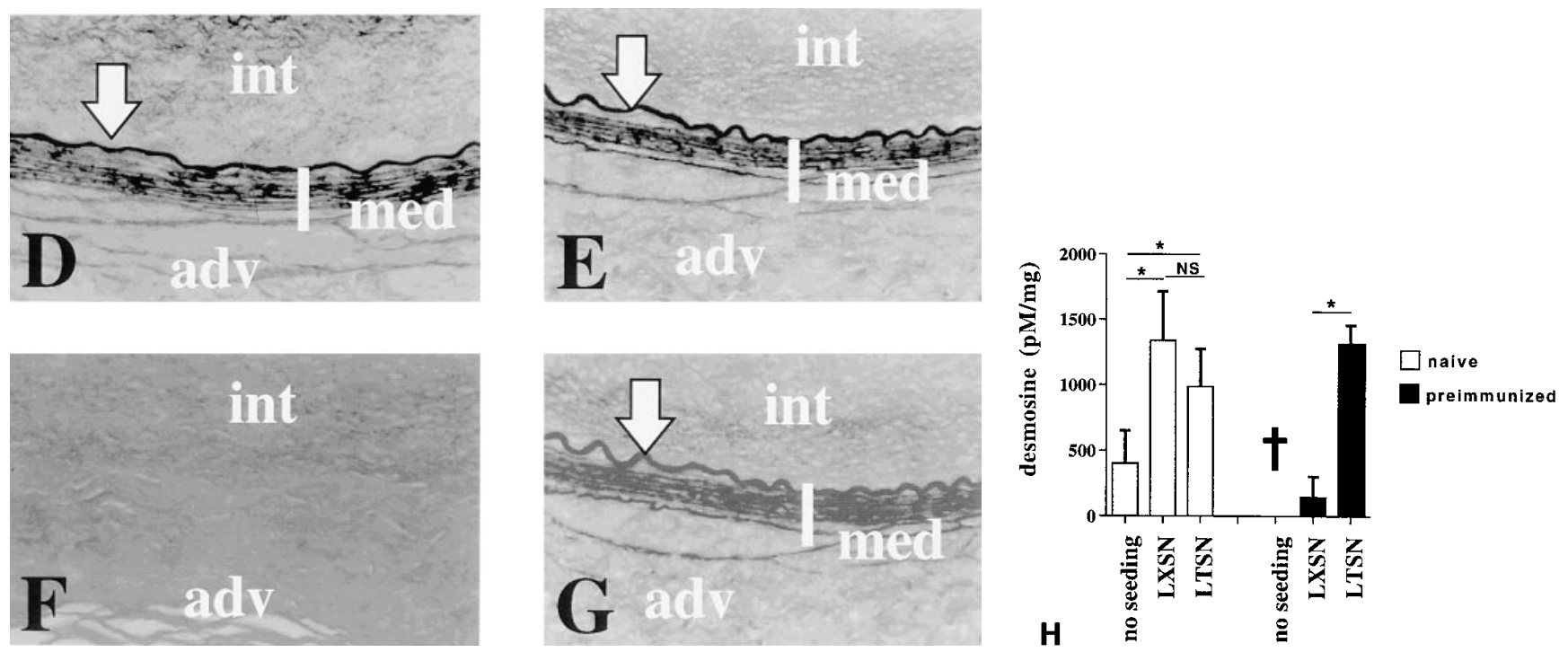

Figure 3. Effect of TIMP-1 overexpression on graft dilation and rupture and elastin network. (A) Macroscopic appearance of a LXSN cell-seeded graft (top) and a LTSN cell-seeded graft (bottom) after 4-wk implantation in preimmunized rats. Arrows show suture lines, and white bars showgraft diameter $(\times 7)$. $(B$ and $C)$ Graphs displaying the diameter and the length of nonseeded, LXSN and LTSN cell-seeded grafts at 4 wk in 

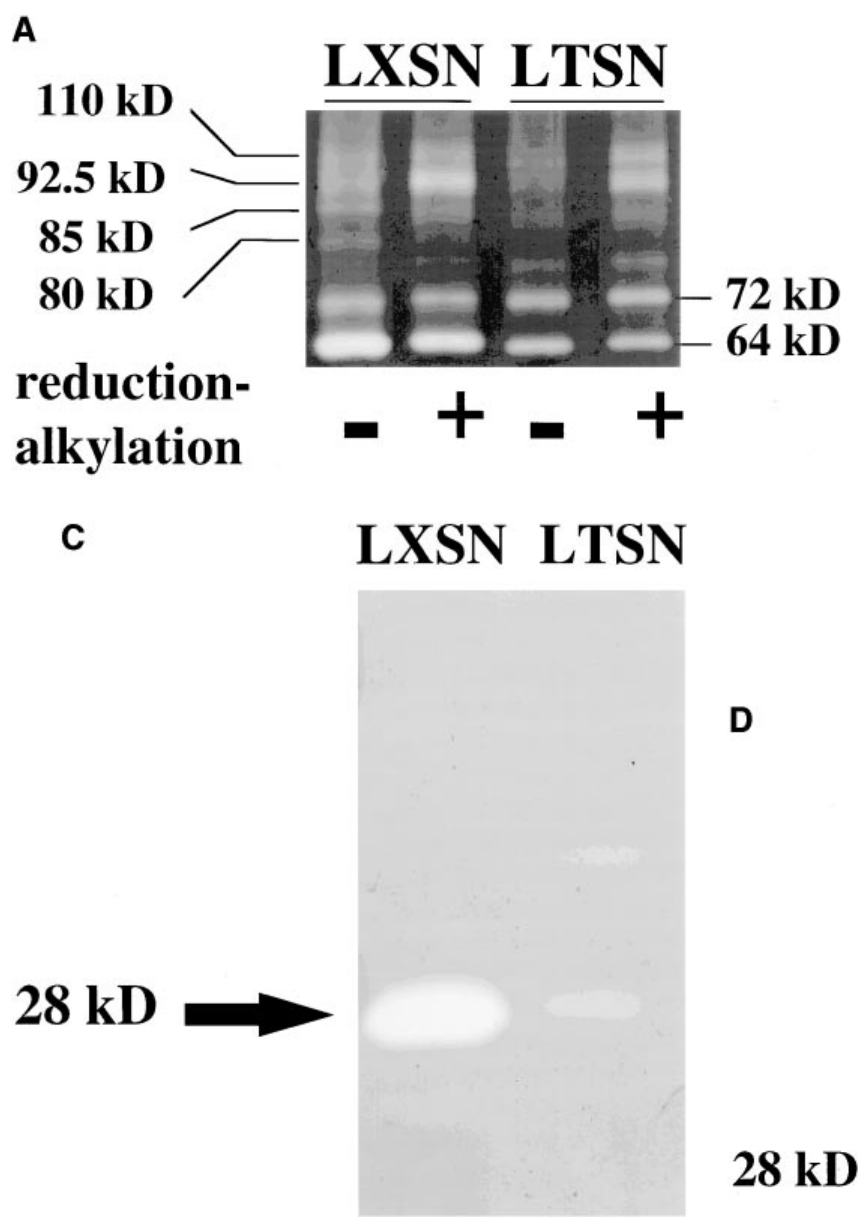

B

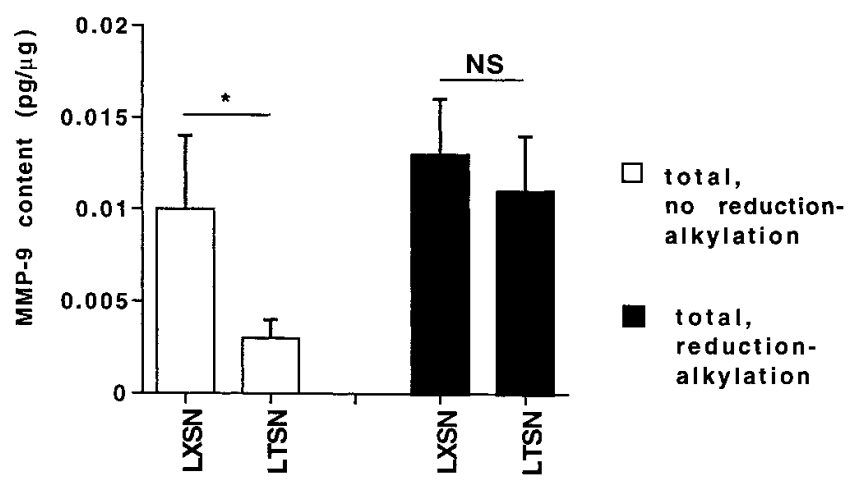

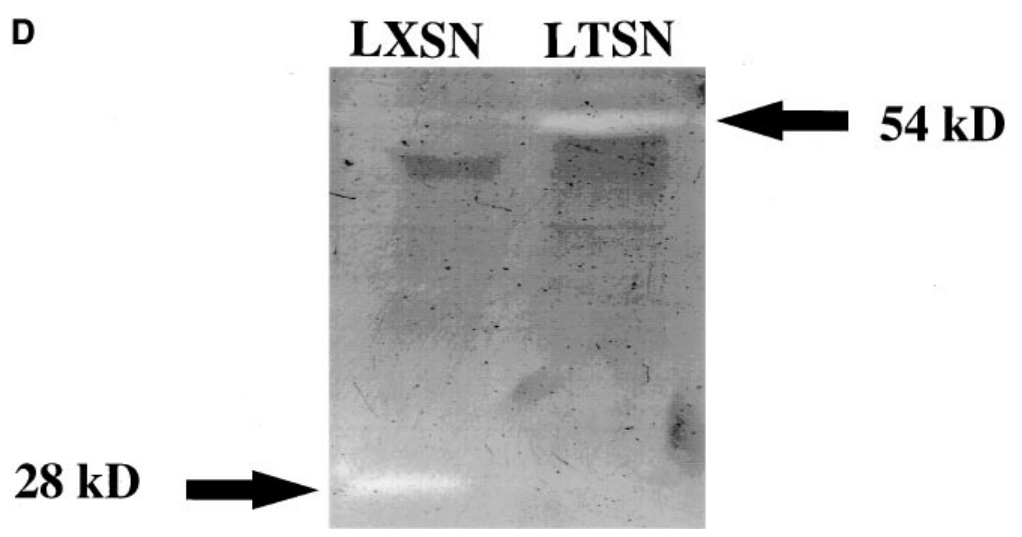

Figure 4. Effect of TIMP-1 overexpression on MMP activities. (A) Gelatin zymogram of extracts from 3-d grafts seeded with LXSN or LTSN cells and implanted into preimmunized rats with and without inactivation of TIMP by reduction-alkylation. $(B)$ Total MMP-9 gelatinolytic activity $(\mathrm{pg} / \mu \mathrm{g}$ protein) with and without inactivation of TIMP by reduction-alkylation. *, $P<0.05$; NS, nonsignificant. $(C)$ Casein zymogram. $(D)$ Elastin zymogram.

production of cytokines and respond to produce various MMPs (25). For example, tumour necrosis factor- $\alpha$ and interleukin 1- $\beta$ are present in human aneurysms and are stimulants of MMP-9 expression in macrophages (17-19). We show in this report that MMP-9 and activated MMP-2 are upregulated during xenograft aneurysmal degeneration and that a further increase of these enzymes is associated with rupture. We also detect 28-kD elastinolytic and caseinolytic MMP activities that might be either MMP-3 or MMP-12. We have shown in other studies that plasminogen activators are also present in this model as they are in human aneurysms $(32,42,43)$. Therefore, the arterial xenograft models many aspects of human aneurysms, including inflammatory infiltration, increased expres- sion of MMPs and plasminogen activators, loss of matrix, vascular dilation, and vascular rupture.

MMP blockade by local TIMP-1 gene transfer. We have used seeded syngeneic smooth muscle cells transduced with a retroviral vector to deliver TIMP-1 to the xenografts. Such a pharmacological strategy has been used by us to define a role for MMPs in intimal hyperplasia after rat carotid balloon injury (27). This approach has several important advantages over conventional pharmacology. In particular, TIMP-1 is a specific physiological inhibitor of MMPs, and local delivery of TIMP-1 reduces the likelihood of a systemic effect of the drug. Doxycycline has also been used to control vasodilation in another model of arterial aneurysm (44). Doxycycline inhibits MMPs

\footnotetext{
Figure 3 legend (Continued)

naive and preimmunized rats. All the unseeded grafts in the preimmunized rats ruptured while four of eight LXSN cell-seeded grafts ruptured. $(D-G)$ Histologic cross sections showing the elastin in the media of a nonruptured LXSN cell-seeded graft $(D$ and $F)$ and a LTSN cell-seeded graft $(E$ and $G)$ after 4-wk implantation in naive $(D$ and $E$ ) and preimmunized $(F$ and $G$ ) rats. Elastin stains as dark fibers in the media (media, white bar; int, intima; $a d v$, adventitia. [ $\times 110])$. $(H)$ Quantification of desmosine, a cross-linking amino acid present only in elastin, after 4 wk in nonseeded, LXSN cell-seeded and LTSN cell-seeded grafts in naive and preimmunized rats. Desmosine content in decellularized guinea pig aortas before implantation was $1732.3 \pm 602.0 \mathrm{pM} / \mathrm{mg}$ protein $(n=6)$. Dagger indicates all grafts ruptured before 4 wk; NS, nonsignificant; * $P<0.05$.
} 
and prevents the degradation of the broad spectrum protease inhibitor alpha-1-antitrypsin (45). However, unlike TIMP-1, doxycycline has many other pharmacological activities (e.g., antimicrobial) and significant toxicities (e.g., teratogenicity and photosensitivity) that are the consequence of systemic administration. The biological effect of TIMP-1 overexpression was demonstrated as early as $3 \mathrm{~d}$ after engraftment. We showed that TIMP-1 protein and activity were generated by transfected seeded cells up to 4 wk. Even though seeded cells accumulate in the intima of the vessel, TIMP-1 was detected not only in the intima but also in the media and adventitia. This pattern suggests that the seeded intima acts as a local drug delivery system to the entire wall. This approach might be of interest for pharmacological control of aneurysms where the biological events driving the disease are primarily located in the media and in the adventitia.

We have analyzed the mechanisms by which TIMP-1 overexpression prevents aneurysm formation and rupture. It is very likely that TIMP-1 inhibits destruction of the wall by blocking MMPs since the elastic layers were preserved and a number of proteases including MMP-9, activated MMP-2, and 28-kD MMP elastinolytic and caseinolytic activities were decreased. The decrease in MMP-9 activity was largely because complexes were formed between MMP-9 and TIMP-1. All TIMPs are able to inhibit MMPs by forming complexes (12). TIMP-1, in addition, can prevent activation of the MMP-9 proform by complex formation and inhibition of MMP-3 activity (12). How TIMP-1 overexpression decreases activated MMP-2 in xenografts is not clear. Because TIMP-1 inactivation by reduction-alkylation did not increase activated MMP-2 levels, it is unlikely that activated MMP-2 was reduced by formation of complexes. Pro-MMP-2 is not activated by MMP-3 (46). It is possible that TIMP-1 inhibited the activator of MMP-2, membrane-type MMP $(47,48)$, although unlike TIMP-2 and TIMP-3, TIMP-1 is not a potent inhibitor of membrane-type MMPs (48). TIMP-1 and the other TIMPs also have activities distinct from MMP inhibition. TIMP-2 stimulates fibroblast proliferation (49), and TIMP-1 has an erythroid potentiation distinct from its capability to inhibit MMPs (50).

Caseinolytic and elastinolytic activities $(28 \mathrm{kD})$ inhibited by EDTA and rTIMP-1 were present in LXSN but not in LTSN cell-seeded grafts. A 54-kD elastase was detected only in LTSN cell-seeded vessels. These two activities might be related to MMP-3 (51) or MMP-12 (52). We have attempted unsuccessfully to detect these MMPs in the xenografts by Western blotting using antibodies to human MMP-3 and mouse MMP-12 (data not shown). Gelatinases MMP-2 and MMP-9 $(13,14,48,53,54)$ as well as MMP-12 (54) can degrade insoluble elastin. Their blockade by TIMP-1 overexpression could account for the preservation of medial elastin in the LTSN cell-seeded vessels. Although the results of the TIMP-1 experiments provide clear support for the hypothesis that matrix degradation by MMPs is an important part of aneurymal degeneration, they do not define the role of each of the MMPs. Such a demonstration will require specific blocking reagents or experiments in mice in which one or more of the genes has been deleted (33).

Control LXSN cells seeded onto the grafts were able to prevent aneurysm formation in naive recipients and decrease rupture in preimmunized recipients. The preservation of elastin in the media paralleled the inhibition of aneurysm formation and rupture. Reverse zymograms demonstrated TIMP-2 activity in LXSN cell-seeded as well as LTSN cell-seeded graft extracts. These results raise the possibility that the protective effect of LXSN cells was mediated in part by TIMP-2 production. However, the effect of LXSN cells was limited as shown by rupture and aneurysmal degeneration in preimmunized animals, a situation where MMP-9 activity in the graft is further increased. Complete protection against aneurysm formation and rupture could be obtained only by a further increase in TIMP activity achieved by the introduction of cells transduced with TIMP-1 cDNA. This result emphasizes the quantitative aspect of the inhibitory pharmacology of MMPs in aneurysms.

These studies provide support for the conclusion that excessive MMP activity throughout the vessel wall is an important cause of aneurysmal degeneration. Our pharmacological approach to restoring a normal proteolytic balance suggests a novel strategy for managing human aortic aneurysmal disease. At present, aneurysms are managed by close observation and vascular reconstruction when the vessels have dilated to a critical size. No pharmacology to suppress the formation of aneurysms exists. It might now be possible by local gene transfer to block aneurysmal expansion and thereby reduce the risk of rupture and the need for surgery.

\section{Acknowledgments}

These studies were supported by grant HL 18645 from the National Institutes of Health, and a grant from the F. Hoffmann-LaRoche, Inc. E. Allaire was supported by a grant from Laboratoire L. Lafon.

\section{References}

1. Baxter, B.T., G.S. McGee, V.P. Shively, I.A.S. Drummond, S.N. Dixit, M. Yamaushi, and W.H. Pearce. 1992. Elastin content, cross-links, and mRNA in normal and aneurysmal human aorta. J. Vasc. Surg. 16:192-200.

2. MacSweeney, S.T., J.T. Powell, and R.M. Greenhalgh. 1994. Pathogenesis of abdominal aortic aneurysm. Br. J. Surg. 81:935-941.

3. Anidjar, S., and E. Kieffer. 1992. Pathogenesis of acquired aneurysms of the abdominal aorta. Ann. Vasc. Surg. 6:298-305.

4. Ernst, C.B. 1993. Abdominal aortic aneurysm. N. Engl. J. Med. 328:11671172.

5. Koch, A.E., G.K. Haines, R.J. Rizzo, J.A. Radosevich, R.M. Pope, P.G Robinson, and W.H. Pearce. 1990. Human abdominal aortic aneurysms. Immunopathologic analysis suggesting an immune-mediated response. Am. J. Pathol. 137:1199-1213.

6. Brophy, C.M., J.M. Reilly, G.J. Smith, and M.D. Tilson. 1991. The role of inflammation in nonspecific abdominal aortic aneurysm disease. Ann. Vasc. Surg. 5:229-233.

7. Freestone, T., R.J. Turner, A. Coady, D.J. Higman, R.M. Greenhalgh, and J.T. Powell. 1995. Inflammation and matrix metalloproteinases in the enlarging abdominal aortic aneurysm. Arterioscl. Thromb. Vasc. Biol. 15:11451151 .

8. Dobrin, P.B., W.H. Baker, and W.C. Gley. 1984. Elastolytic and collagenolytic studies of arteries. Implications for the mechanical properties of aneurysms. Arch. Surg. 119:405-409.

9. Anidjar, S., J.L. Salzmann, D. Gentric, P. Lagneau, J.P. Camilleri, and J.B. Michel. 1990. Elastase-induced experimental aneurysm in rat. Circulation. 82:973-981.

10. Allaire, E., P. Bruneval, C. Mandet, J.P. Becquemin, and J.B. Michel. 1997. The immunogenicity of the arterial extracellular matrix in arterial xenografts. Surgery. 122:73-81.

11. Mesh, C.L., B.T. Baxter, W.H. Pearce, R.L. Chisholm, G.S. McGee, and J.S. Yao. 1992. Collagen and elastin gene expression in aortic aneurysms. Surgery. 112:256-261.

12. Birkedal-Hansen, H., W.G.I. Moore, M.K. Bodden, L.J. Windsor, B. Birkedal-Hansen, A. DeCarlo, and J.A. Engler. 1993. Matrix metalloproteinases: a review. Crit. Rev. Oral Biol. Med. 4:197-250.

13. Murphy, G., M.I. Cockett, R.V. Ward, and A.J. Docherty. 1991. Matrix metalloproteinase degradation of elastin, type IV collagen and proteoglycan. A quantitative comparison of the activities of $95 \mathrm{kDa}$ and $72 \mathrm{kDa}$ gelatinases, stromelysins-1 and -2 and punctuated metalloproteinase (PUMP). Biochem. J. 277:277-279. 
14. Katsuda, S., Y. Okada, K. Imai, and I. Nakanishi. 1994. Matrix metalloproteinase-9 (92-kd gelatinase/type IV collagenase equals gelatinase B) can degrade arterial elastin. Am. J. Pathol. 145:1208-1218.

15. Shipley, J.M., G.A.R. Doyle, C.J. Fliszar, Q.Z. Ye, L.L. Johnson, S.D. Shapiro, H.G. Welgus, and R.M. Senior. 1996. The structural basis for the elastinolytic activity of the $92-\mathrm{kDa}$ and $72-\mathrm{kDa}$ gelatinases. J. Biol. Chem. 8:43354341 .

16. Mecham, R.P., T.J. Broekelmann, C.J. Fliszar, S.D. Shapiro, H.G. Welgus, and R.M. Senior. 1997. Elastin degradation by matrix metalloproteinases. Cleavage site specificity and mechanisms of elastolysis. J. Biol. Chem. 272: 18071-18076.

17. Newman, K.M., J. Jean Claude, H. Li, and W.G. Ramey. 1994. Cytokines that activate proteolysis are increased in abdominal aortic aneurysms. Circulation. 90:11224-11227.

18. Pearce, W.H., I. Sweis, J.S. Yao, W.J. McCarthy, and A.E. Koch. 1992. Interleukin-1 beta and tumor necrosis factor-alpha release in normal and diseased human infrarenal aortas. J. Vasc. Surg. 16:784-789.

19. Sarén, P., H.G. Welgus, and P.T. Kovanen. 1996. Alpha and IL-1 beta selectively induce expression of $92-\mathrm{kDa}$ gelatinase by human macrophages. $J$. Immunol. 157:4159-4165.

20. Thompson, R.W., D.R. Holmes, R.A. Mertens, S. Liao, M.D. Botney, R.P. Mecham, H.G. Welgus, and W.C. Parks. 1995. Production and localization of 92-kilodalton gelatinase in abdominal aortic aneurysms. An elastolytic metalloproteinase expressed by aneurysm-infiltrating macrophages. J. Clin. Invest. 96:318-326.

21. McMillan, W.D., B.K. Patterson, R.R. Keen, V.P. Shively, M. Cipollone, and W.H. Pearce. 1995. In situ localization and quantification of mRNA for 92-kD type IV collagenase and its inhibitor in aneurysmal, occlusive, and normal aorta. Arterioscl. Thromb. Vasc. Biol. 15:1139-1144.

22. Vine, N., and J.T. Powell. 1991. Metalloproteinases in degenerative aortic disease. Clin. Science. 81:233-239.

23. Allaire, E., C. Guettier, P. Bruneval, D. Plissonnier, and J.B. Michel. 1994. Cell-free arterial grafts: morphologic characteristics of aortic isografts, allografts, and xenografts in rats. J. Vasc. Surg. 19:446-456.

24. Allaire, E., C. Mandet, P. Bruneval, S. Bensenane, J.P. Becquemin, and J.B. Michel. 1996. Cell and extracellular matrix rejection in arterial concordant and discordant xenografts in rat. Transplantation. 62:794-803.

25. Libby, P. 1995. Molecular bases of the acute coronary syndromes. Circulation. 91:2844-2850.

26. Forough, R., S.T. Nikkari, D. Hasenstab, H. Lea, and A.W. Clowes. 1995. Cloning and characterization of a cDNA encoding the baboon tissue inhibitor of metalloproteinase-1 (TIMP-1). Gene. 163:267-271.

27. Forough, R., N. Koyama, D. Hasenstab, H. Lea, M.M. Clowes, S.T. Nikkari, and A.W. Clowes. 1996. Overexpression of tissue inhibitor of matrix metalloproteinase- 1 inhibits vascular smooth muscle cell functions in vitro and in vivo. Circ. Res. 79:812-820.

28. Miller, A.D., and G.J. Rosman. 1989. Improved retroviral vectors for gene transfer and expression. Biotechniques. 7:980-990.

29. Starcher, B., and M. Conrad. 1995. A role for neutrophil elastase in the progression of solar elastosis. Connect. Tissue. Res. 31:133-140.

30. Abramson, S.R., G.E. Conner, H. Nagase, I. Neuhaus, and J.F.J. Woessner. 1995. Characterization of rat uterine matrilysin and its cDNA. Relationship to human pump-1 and activation of procollagenases. J. Biol. Chem. 270: 16016-16022.

31. Dean, D.D., J. Martel-Pelletier, J.-P. Pelletier, D.S. Howell, and J.F. Woessner. 1989. Evidence for metalloproteinase and metalloproteinase inhibitor imbalance in human osteoarthritic cartilage. J. Clin. Invest. 84:678-685.

32. Allaire, E., D. Hasenstab, R.D. Kenagy, M.M. Clowes, and A.W. Clowes. 1997. Plasminogen activator inhibitor type-1 (PAI-1) overexpession by retrovirally transduced cell seeding prevents arterial aneurysm formation and rupture in rats. Circulation. 96:1-171. (Abstr.)

33. Carmeliet, P., L. Moons, R. Lijnen, M. Baes, V. Lemaître, P. Tipping, A. Drew, Y. Eeckhout, F. Lupu, and D. Collen. 1997. Urokinase-generated plasmin activates matrix metalloproteinases during aneurysm formation. Nat. Genet. 17:439-444.

34. Camiolo, S.M., M.R. Siuta, and J.M. Madeja. 1982. Improved medium for extraction of plasminogen activator from tissue. Prep. Biochem. 12:297-305.
35. Clowes, A.W, M.M. Clowes, Y.P.T. Au, and M.A. Reidy. 1990. Smooth muscle cells express urokinase during mitogenesis and tissue-type plasminogen activator during migration in injured rat carotid artery. Circ. Res. 67:61-67.

36. Bendeck, M.P., N. Zempo, A.W. Clowes, R.E. Galardy, and M.A. Reidy. 1994. Smooth muscle cell migration and matrix metalloproteinase expression after arterial injury in the rat. Circ. Res. 75:539-545.

37. Zempo, N., R.D. Kenagy, Y.P. Au, M. Bendeck, M.M. Clowes, M.A. Reidy, and A.W. Clowes. 1994. Matrix metalloproteinases of vascular wall cells are increased in balloon-injured rat carotid artery. J. Vasc. Surg. 20:209-217.

38. Holmes, D.R., A. Lopez-Candales, S. Liao, and R.W. Thompson. 1996. Smooth muscle cell apoptosis and p53 expression in human abdominal aortic aneurysms. Ann. NY Acad. Sci. 800:286-287.

39. Tilson, M.D. 1995. Similarities of an autoantigen in aneurysmal disease of the human abdominal aorta to a $36-\mathrm{kDa}$ microfibril-associated bovine aortic glycoprotein. Biochem. Biophys. Res. Com. 213:40-43.

40. Gregory, A.K., N.X. Yin, J. Capella, S. Xia, K.M. Newman, and M.D. Tilson. 1996. Features of autoimmunity in the abdominal aortic aneurysm. Ann. Surg. 131:85-88.

41. Feldman, M., F.M. Brennan, and R.N. Maini. 1996. Rhumatoid arthritis Cell. 85:307-310.

42. Newman, K.M., Y. Ogata, A.M. Malon, E. Irizarry, R.H. Gandhi, and H. Nagase. 1994. Identification of matrix metalloproteinases 3 (stromelysin-1) and 9 (gelatinase B) in abdominal aortic aneurysm. Arterioscler. Thromb. 14: $1315-1320$.

43. Newman, K.M., J. Jean Claude, H. Li, J.V. Scholes, Y. Ogata, H. Nagase, and M.D. Tilson. 1994. Cellular localization of matrix metalloproteinases in the abdominal aortic aneurysm wall. J. Vasc. Surg. 20:814-820.

44. Petrinec, D., S. Liao, D.R. Holmes, J.M. Reilly, W.C. Parks, and R.W. Thompson. 1996. Doxycycline inhibition of aneurysmal degeneration in an elastase-induced rat model of abdominal aortic aneurysm: preservation of aortic elastin associated with suppressed production of $92 \mathrm{kD}$ gelatinase. J. Vasc. Surg. 23:336-346.

45. Sorsa, T., O. Lindy, Y.T. Konttinen, K. Suomalainen, T. Ingman, H. Saari, S. Halinen, H.S. Lee, L.M. Golub, J. Hall, and S. Simon. 1993. Doxycyclin in the protection of serum alpha-1-antitrypsin from human neutrophil collagenase and gelatinase. Antimicrob. Agents Chemother. 37:592-594.

46. Okada, Y., T. Morodomi, J.J. Enghild, K. Suzuki, A. Yasui, I. Nakanishi, G. Salvesen, and H. Nagase. 1990. Matrix metalloproteinase 2 from human rheumatoid synovial fibroblasts. Purification and activation of the precursor and enzymic properties. Eur. J. Biochem. 194:721-730.

47. Pei, D., and S.J. Weiss. 1996. Transmembrane-deletion mutants of the membrane-type matrix metalloproteinase-1 process progelatinase A and express intrinsic matrix-degrading activity. J. Biol. Chem. 271:9135-9140.

48. Butler, G.S., H. Will, S.J. Atkinson, and G. Murphy. 1997. Membranetype-2 matrix metalloproteinase can initiate the processing of progelatinase A and is regulated by the tissue inhibitors of metalloproteinases. Eur. J. Biochem. 244:653-657.

49. Corcoran, M.L., and W.G. Stetler Stevenson. 1995. Tissue inhibitor of metalloproteinase-2 stimulates fibroblast proliferation via a cAMP-dependent mechanism. J. Biol. Chem. 270:13453-13459.

50. Chesler, L., D.W. Golde, N. Bersch, and M.D. Johnson. 1995. Metalloproteinase inhibition and erythroid potentiation are independent activities of tissue inhibitor of metalloproteinases-1. Blood. 86:4506-4515.

51. Okada, Y., H. Nagase, and E.D.J. Harris. 1987. Matrix metalloproteinases 1,2 , and 3 from rheumatoid synovial cells are sufficient to destroy joints. $J$. Rheumatol. 14:41-42.

52. Shapiro, S.D., D.K. Kobayashi, and T.J. Ley. 1993. Cloning and characterization of a unique elastolytic metalloproteinase produced by human alveolar macrophages. J. Biol. Chem. 268:23824-23829.

53. Senior, R.M., G.L. Griffin, C.J. Fliszar, S.D. Shapiro, G.I. Goldberg, and H.G. Welgus. 1991. Human 92- and 72-kilodalton type IV collagenases are elastases. J. Biol. Chem. 266:7870-7875.

54. Mecham, R.P., T.J. Broekelmann, C.J. Fliszar, S.D. Shapiro, H.G. Welgus, and R.M. Senior. 1997. Elastin degradation by matrix metalloproteinases. Cleavage site specificity and mechanisms of elastolysis. J. Biol. Chem. 272: 18071-18076. 